\title{
XXX.-Account of the Remains of an Ancient Camp near Bayonne. By S. Baring Gould, Esq. of Lew Trenchard.
}

\author{
Read December 11, 1851.
}

Near Cambo, a small watering-place at the distance of about twelve miles from Bayonne, in the department of the Basses Pyrenees, France, are the remains of a camp which native antiquaries have variously conjectured as being of Roman, Celtic, Saracen, or ancient Cantabrian construction. It bears not the slightest resemblance to the three former, and from its being situated in the very centre of the Basque districts may be considered as the work of that people, perhaps at the time when attacked by the Romans and driven into their mountain fastnesses, where they manfully stood their ground in defiance of the imperial eagles, and which is the subject of the "Lelo," a national chant, a translation of which I may be pardoned for inserting :

I. "The strangers of Rome marched against Biscay ; and thro' Biscay sounded the song of war. Octavian was lord of the world, while Cecobidi was the leader of the men of Biscay.

II. "By sea, by land, Octavian has besieged us. The sandy plains belong to the Romans, but to us the woods and caverns on the mountain side.

III. "Camped in a favourable place, our hearts grow bold, and while wielding our arms we shake off fear; but we starve.

IV. "Although our foes are clad in strong harness, our limbs unfettered are free and light. For five years, night and day, has the siege continued unceasingly.

V. "When one on our side falls, fifteen of our enemies pave the way for his soul. They are many ; our army is but a little band. At length peace comes, \&c."

The Camp, which was the work of these people, and made perhaps at the time referred to in the song, is most singular in its construction, being composed of a multiplicity of ditches, but without any traces of a vallum or rampart of any kind.

The hill, which has been moulded into a fort or retreat, is situated near the issue of the Nive from the mountains, on the summit of the highest of which are to be seen the remains of a wall, as I have been informed, but was unfortunately unable to 
verify this by a personal visit. The hill of which the camp is formed is of a loose gravelly soil, upon sandstone, but the rock to all appearance has not been cut away in the ditches, but only the gravel removed. The summit of the hill appears to have been levelled into a kind of plateau that rises out of the fosses which surround it on all sides, leaving only a narrow neck of land uncut.

A description of this singular manner of castrametation will be best understood by a reference to the annexed vignette and sections. A B is the plateau, rendered level
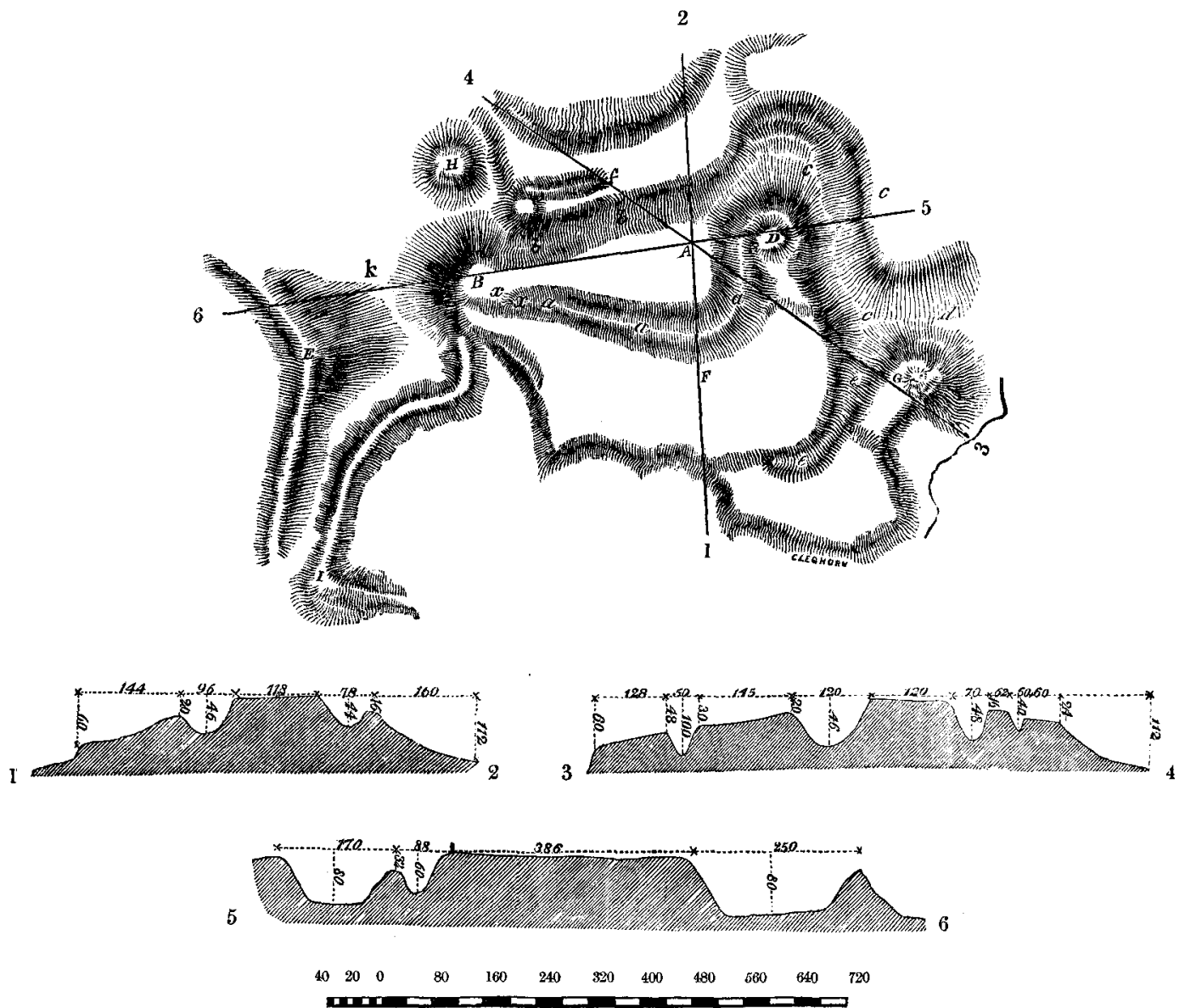

for the purpose of encampment, and is surrounded by the ditches $a a, b b$. The ditch $a$ winds round the conical mound $\mathrm{D}$, forming a basin at $c$, and then descends gradually to $d$, where a small stream flows by. From this approach or fosse a smaller ditch $(e)$ branches off to the left on ascending, passing a second conical hill $(G)$. The part $f$ is a portion of the same hill as the camp, but is considerably lower than A B, which commands it. 
The ditch $b b$, which cuts off the western slope of the hill, opens into a very large basin $(k)$, to the level of which the plain A B descends precipitately. A small fosse $(f)$ branches out of this basin $(k)$, and runs a short distance parallel to the ditch $b b$. Near its mouth stands a remarkable bell-shaped mound $(\mathrm{H})$, whose use, unless it were sepulchral, is inexplicable. Two narrow ridges (E, I) confine this great basin on the east side, and contracting inclose a kind of road bounded on either side by these two abrupt mounds, which are of considerable height, and so sharp on the top still as to leave barely room for one to walk. The high and almost pyramidical mound marked I, which is placed at the angle of the southern ridge, rises almost to the same height as the great plateau, but is so steep as to be climbed with difficulty, and leaves only just room sufficient to stand on the top. I had not time at my disposal to follow out these ridges and trace them out, but they run for a considerable distance, turning after at a right angle to their former direction and inclosing the road, if such the hollow between them may be considered. The sides of the ditches are steep almost to abruptness, but leave a level spot at the bottom of the fosses.

It may be remarked that at $x$ the ditch or covered way $a$ rises gradually to the level of B. I cannot remember whether the same fact applies to $e$. If I may offer a supposition on the use of some of the ditches, it is, that the broad one $d c c b$ was used both for giving access to the plateau and as a covered way for descending to the stream, which former might also be obtained from the basin $k$, by passing up $c c$ and winding through $a a a$, and ascending to the plain B A by $x$. There is room for three or four to walk abreast with ease at the bottom of these ditches : in $c c d$ there is space for numbers more. The depth of the ditches will be seen by reference to the three sections, and I add a view of the mounds $E$ and

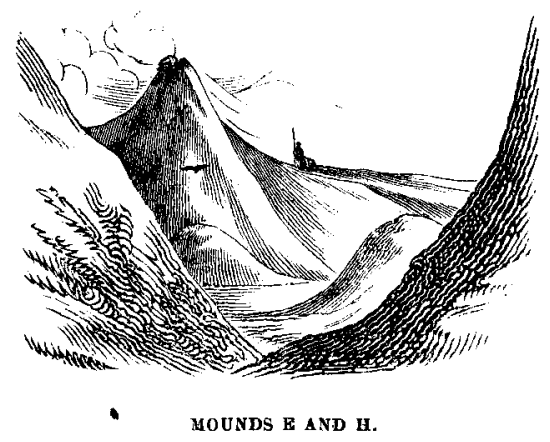




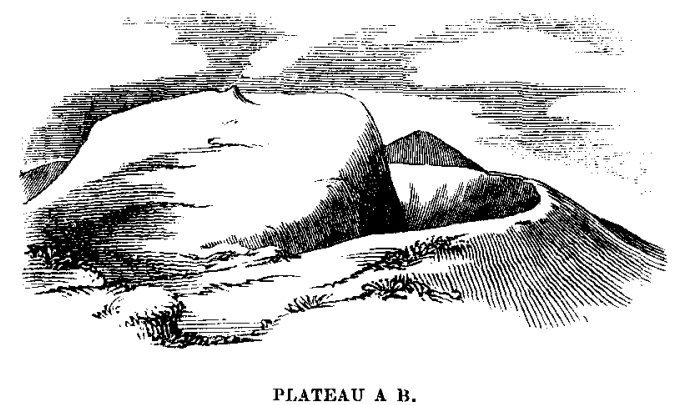

$\mathrm{H}$ from the mouth of the fosse $b$; also a sketch of the plateau from $\mathrm{B}$, shewing the $\operatorname{ditch} a a$; and a general view of the camp from the distance. The scale for the plan and the sections is the same.

P.S.-It may be as well to remark that at A, the highest point of the camp, is a small upright stone from two to three feet high.

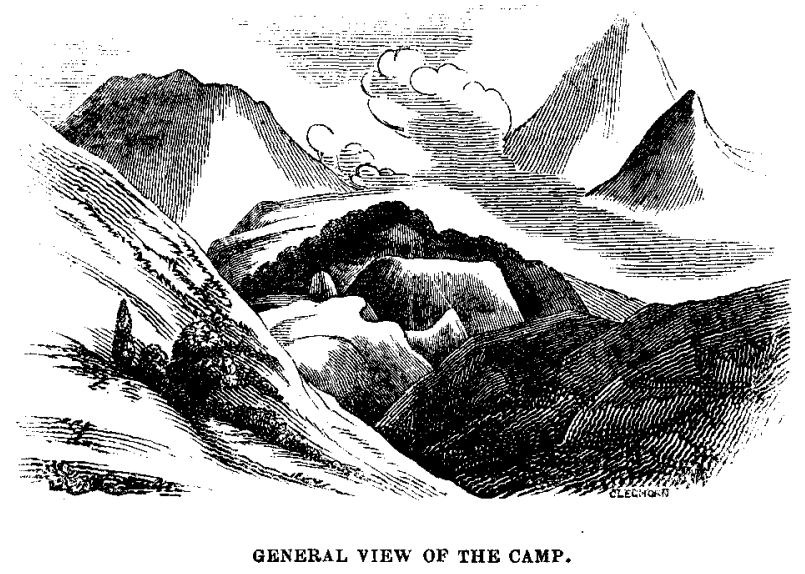

